\title{
Prevalence of aspirin and clopidogrel resistance in neurovascular stenting: a single-center experience
}

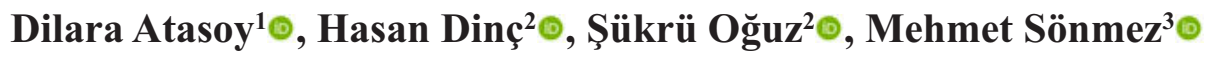 \\ ${ }^{1}$ Department of Radiology, Sivas Numune Hospital, Sivas, Turkey \\ ${ }^{2}$ Department of Radiology, Karadeniz Technical University Faculty of Medicine, Farabi Hospital, Trabzon, Turkey \\ ${ }^{3}$ Department of Internal Medicine, Division of Hematology, Karadeniz Technical University Faculty of Medicine, Farabi Hospital, \\ Trabzon, Turkey
}

\begin{abstract}
Objectives: The objective of this study was to determine the frequency of aspirin and clopidogrel resistance of patients undergoing neurovascular stenting procedure in the interventional radiology unit.

Methods: The Multiplate ${ }^{\circledR}$ Analyzer (Roche Diagnostics, Germany) test data of 250 patients who underwent carotid or intracranial artery stenting due to atherosclerotic stenosis or treatment of intracranial aneurysms between 2013-2017 in the Interventional Radiology Unit of our hospital were evaluated retrospectively to detect the aspirin and clopidogrel resistance. Aspirin or clopidogrel resistance defined as the higher AUC value than $40 \mathrm{U}$ and $46 \mathrm{U}$, respectively. The patients who did not have a result of the Multiplate ${ }^{\circledR}$ test; had anemia, known coagulation disorder or thrombocytopenia were excluded.

Results: Among the 172 patients who met the inclusion criteria, $59(34.3 \%)$ were those who had an intracranial stent during aneurysm treatment, and $113(65.7 \%)$ had carotid stenting due to atherosclerotic stenosis. The prevalence of aspirin resistance was $9.4 \%$ (16/170) whereas that of clopidogrel resistance was $23.8 \%(41 / 172)$. Among the patients with atherosclerotic stenosis, aspirin resistance accounting for $3.6 \%$, and clopidogrel resistance was $23.0 \%$. Furthermore, the resistance in the patients with stent-assisted coiling for aneurysm treatment was $20.7 \%$ for aspirin and $25.4 \%$ for clopidogrel.

Conclusions: In our study, the prevalence of aspirin resistance was found $9.4 \%$ and clopidogrel resistance $23.8 \%$ in patients who had neurovascular stenting. The effect of this condition on clinical outcomes in these patients should be investigated by randomized controlled trials.

Keywords: Neurovascular stenting, aspirin resistance, clopidogrel resistance, multiplate test, antiplatelet resistance
\end{abstract}

D ual antiplatelet treatment with aspirin (acetylsalicylic acid) and clopidogrel has been readily accepted regiment of antithrombotic therapy in patients undergoing neurovascular stenting [1]. Although these antithrombotics have been used in patients as premedication and after neurovascular stenting procedure, thromboembolic complications have still been encountered during or/and after the procedure [2].
Insufficient in vivo platelet inhibition with aspirin and clopidogrel have been accused of thromboembolic complications theoretically. If inadequate platelet inhibition is demonstrated with a laboratory test, the terms 'resistance to aspirin or clopidogrel', 'low response to aspirin-clopidogrel', or 'nonresponse to aspirin-clopidogrel' have been used. In vitro laboratory tests detecting platelet function, namely Multiplate ${ }^{\circledR}$, 
VerifyNow ${ }^{\circledR}$, Light Transmission Aggregometry (LTA), PFA-100 (Platelet Function Assay), VASP (vasodilator-stimulated phosphoprotein), have been used excessively among patients with cardiovascular intervention in order to indicate patients with inadequate platelet inhibition [3]. This trend has been adopted in the field of neurovascular intervention by some centres and the Multiplate ${ }^{\circledR}$ test has been used in our neurovascular interventional unit for this purpose.

Providing antiplatelet drug resistance could be determined before neurovascular stenting, antiplatelet dosage and combination might be adjusted on an individual basis to prevent new thromboembolic events [4]. Therefore, it might be important to know the inadequate response to aspirin and clopidogrel in patients who will have neurovascular stent-placement procedures. In this study, we aimed to detect the frequency of aspirin and clopidogrel resistance in patients undergoing neurovascular stenting in the interventional radiology unit of our hospital.

\section{METHODS}

\section{Patient Group}

Patients who underwent elective intracranial or extracranial stent placement with different indications at the Interventional Radiology Unit of our (the name hidden for blinded review) University, Faculty of Medicine, Department of Radiology between January 1, 2013 and January 31, 2017 were assessed.

The patients who did not receive aspirin or clopidogrel for any reason or did not have a complete result of the resistance test; had anemia ( $\mathrm{Hg}$ level $<8 \mathrm{~g} / \mathrm{dl}$ ), known coagulation disorder or thrombocytopenia $(<$ $50.000 / \mathrm{m}^{3}$ ), polycythemia, leukopenia (leukocytes $<$ $4.000 / \mathrm{mm}$ ), bone marrow disease or blood transfusion were excluded. In addition, those whom taken blood samples could not be processed between 30 minutes and 3 hours were not included.

Records of patients in the study were retrospectively reviewed and the data were collected including age, sex, and presence of concomitant diseases such as hypertension, diabetes, cerebrovascular event (CVO), coronary artery disease (CAD), hypercholesterolemia, chronic kidney disease (CKD) and chronic liver disease. Moreover, results of the fasting blood samples obtained on the day before or on the day of the procedure were evaluated to note blood glucose, creatinine, hemoglobin, platelet, and leukocyte counts.

Routine screening for clinically silent ischemic strokes with diffusion-weighted imaging was not performed. Post-procedural images of patients (unenhanced computed tomography or magnetic resonance imaging) were retrospectively examined for possible new ischemic findings by comparison with pre-procedural imaging.

\section{Medication of Patients}

Patients scheduled for elective neurovascular stent placement received $100 \mathrm{mg}$ aspirin and $75 \mathrm{mg}$ clopidogrel per day for 7 days prior to the procedure normally. If there were less than 7 days to the procedure, $300 \mathrm{mg}$ clopidogrel and aspirin per day were given for 3 days and then continued with $100 \mathrm{mg}$ aspirin and 75 mg clopidogrel daily. None of our patients received $600 \mathrm{mg}$ clopidogrel as a loading dose just before the day of the procedure.

If the clopidogrel resistance was demonstrated by Multiplate ${ }^{\circledR}$ test, the premedication was adjusted as $500 \mathrm{mg}$ of ticlopidine and $100 \mathrm{mg}$ of aspirin for 7 days before the procedure. In case of still antiplatelet resistance presence, prasugrel $10 \mathrm{mg}$ per day alone was given 7 days before the procedure.

\section{Multiplate ${ }^{\circledR}$ test}

Venous blood samples were collected 24 hours before the procedure from the peripheral antecubital vein by nurses. Blood samples were filled into hirudin filled tubes after which they were sent to the hematology laboratory within 30 minutes. Platelet function tests were studied with the Multiplate ${ }^{\circledR}$ analysis system (Fig. 1). Blood samples were stored at room temperature for 30 minutes. Platelet aggregation was evaluated using the impedance method within 30-180 minutes in total after samples were collected. 300 microliters of the blood sample were taken and were diluted again with 300 microliters of $0.9 \%$ saline at room temperature. 20 microliters ADP or ASP test agents were added into these sample after 3 minutes incubation period.

The results were obtained by calculating the area under the curve (AUC) at the end of the 6 minute evaluation period. The recommended range for AUC values is $71-115 \mathrm{U}$ for aspirin and $57-113 \mathrm{U}$ for clopidogrel. Aspirin Multiplate ${ }^{\circledR}$ test results above 40U 


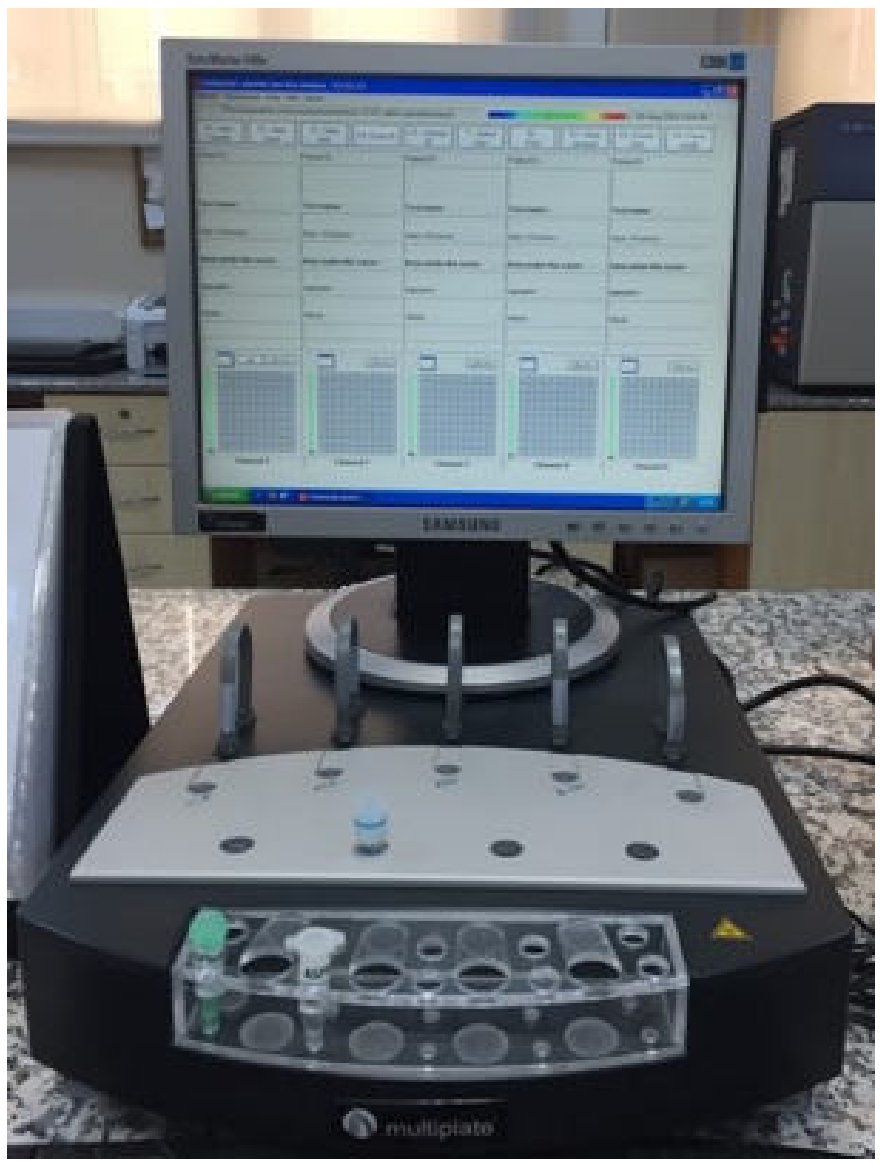

Fig. 1. Multiplate Test Machine. Multiplate test machine in our hospital is located in Hematology laboratary; however, it is possible to be situated and utilized it with a trained staff in interventional radiology units.

were recorded as the group showing aspirin resistance while for clopidogrel, those with a result above $46 \mathrm{U}$ were recorded as with clopidogrel resistance. Followup platelet-activity testing was not performed after the procedure.

\section{Statistical Analysis}

SSPS version 23.0 was used for statistical analysis. The patients were divided into two groups as stenting due to atherosclerotic stenosis and stent-assisted coil embolization for aneurysm treatment. For these two groups, separately, and all patients are searched for aspirin and clopidogrel resistance. The two groups were compared in terms of the frequency of resistance. Clinical characteristics were also compared between these two groups, as well as the resistant versus nonresistant groups. The independent samples t-test, Mann Whitney U test, and Chi square tests were used to determine the correlations between the variables. A $p$ value of $<0.05$ was considered statistically significant. The study was approved by the ethics committee of our hospital.

\section{RESULTS}

In this study, 250 patients who underwent neurovascular stenting in the Interventional Radiology Unit of our hospital between 2013 and 2017 were identified. 78 of these were excluded since 74 of them those whom could not be reached the complete Multiplate ${ }^{\circledR}$ test results, 2 of them had severe anemia and the remaining 2 had severe thrombocytopenia. 57 (33.1\%) of the patients were female while $115(66.9 \%)$ were male. The mean age was $65.6(20-92)$ years. Of the remaining 172 patients, $59(34.3 \%)$ were those the intracranial stents were implanted during aneurysm embolization, and $113(65.7 \%)$ were the ones who had stenting for the treatment of atherosclerotic stenosis. Flow diverter devices were used in $35(20.3 \%)$ patients who had stent placement during aneurysm treatment. The prevalance of aspirin resistance was $9.4 \%$ $(16 / 170)$ in all patients whereas that of clopidogrel was $23.8 \%$ (41/172). There were $9(5 \%)$ patients with both aspirin and clopidogrel resistance.

When the group with aspirin resistance was compared with the group without resistance, a significant difference was found between the ages $(p=0.005)$. The mean age was $57.4 \pm 12.2$ years in the resistant group while it was $66.6 \pm 12.8$ years in the nonresistant group. There were no significant difference between resistant and non-resistant groups in terms of concomitant diseases; diabetes, hypertension, coronary artery disease, and dyslipidemia. Moreover, no significant difference was found between the two groups concerning thromboembolic findings in the cranial MR or CT (Table 1).

When the group with clopidogrel resistance and the one without resistance were compared; the presence of diabetes was found $63.4 \%$ in the resistant group, while it was $26.0 \%$ in the non-resistant group $(p<0.001)$. There was no significant difference between the two groups in other parameters (Table 2).

Aspirin resistance was 3.6\% and clopidogrel resistance was $23.0 \%$ in the stent-implanted group due to atherosclerotic stenosis, whereas the resistance in the stent-assisted aneurysm treatment group was 
Table 1. Comparison between the group with aspirin resistance and without resistance

\begin{tabular}{lccc}
\hline \multicolumn{1}{c}{ Parameter } & $\begin{array}{c}\text { Group with Aspirin } \\
\text { resistance } \\
(\mathbf{n}=\mathbf{1 6})\end{array}$ & $\begin{array}{c}\text { Group without Aspirin } \\
\text { resistance } \\
(\mathbf{n}=\mathbf{1 5 4})\end{array}$ & $\boldsymbol{p}$ value \\
\hline Age (years) & $57.38 \pm 12.2$ & $66.61 \pm 12.8$ & $\mathbf{0 . 0 0 5}$ \\
\hline Gender (female) & $43.8 \%$ & $31.2 \%$ & 0.457 \\
\hline Diabetus mellitus & $37.5 \%$ & $33.8 \%$ & 0.982 \\
Hypertension & $56.3 \%$ & $63.0 \%$ & 0.796 \\
\hline Coronary arterial disease & $25.0 \%$ & $26.0 \%$ & 1.000 \\
Dyslipidaemia & $18.8 \%$ & $38.3 \%$ & 0.203 \\
Chronic kidney disease & $0.0 \%$ & $3.2 \%$ & 1.000 \\
\hline Radiologic thromboembolic & $20.0 \%$ & $32.2 \%$ & 0.720 \\
findings & & & 0.026 \\
\hline Creatinine $(\mathrm{mg} / \mathrm{dl})$ & $0.77 \pm 0.2$ & $0.89 \pm 0.25$ & 0.187 \\
Glucose $(\mathrm{mg} / \mathrm{dl})$ & $144.9 \pm 65.2$ & $132.5 \pm 91.7$ & 0.839 \\
\hline Leukocyte $\left(\times 10^{9}\right)$ & $8.4 \pm 3.2$ & $8.6 \pm 3.2$ & 0.892 \\
\hline Platelet $\left(\times 10^{9}\right)$ & $225.6 \pm 72.8$ & $229.2 \pm 71.1$ & 0.764 \\
\hline Hemoglobin $(\mathrm{g} / \mathrm{dl})$ & $12.8 \pm 1.3$ & $12.9 \pm 1.6$ & \\
\hline
\end{tabular}

Data are shown as mean \pm standard deviation or $\mathrm{n}(\%)$

Table 2. Comparison between the group with clopidogrel resistance and without resistance

\begin{tabular}{lccc}
\hline \multicolumn{1}{c}{ Parameter } & $\begin{array}{c}\text { Group with } \\
\text { Clopidogrel resistance } \\
(\mathbf{n = 4 1 )}\end{array}$ & $\begin{array}{c}\text { Group without Clopidogrel } \\
\text { resistance } \\
(\mathbf{n = 1 3 1 )}\end{array}$ & $p$ value \\
\hline Age $($ years & $65.9 \pm 11.4$ & $65.60 \pm 13.4$ & 0.960 \\
Gender (female) & $36.6 \%$ & $32.1 \%$ & 0.729 \\
\hline Diabetus mellitus & $63.4 \%$ & $26.0 \%$ & $<\mathbf{0 . 0 0 1}$ \\
Hypertension & $68.3 \%$ & $61.1 \%$ & 0.516 \\
Coronary arterial disease & $25.0 \%$ & $26.0 \%$ & 0.259 \\
Dyslipidaemia & $41.5 \%$ & $34.4 \%$ & 0.521 \\
Chronic kidney disease & $4.9 \%$ & $2.3 \%$ & 0.594 \\
Radiologic thromboembolic & $20.0 \%$ & $34.7 \%$ & 0.261 \\
findings & & & \\
Creatinine $(\mathrm{mg} / \mathrm{dl})$ & $0.88 \pm 0.28$ & $0.88 \pm 0.24$ & 0.934 \\
Glucose $(\mathrm{mg} / \mathrm{dl})$ & $128.4 \pm 51.4$ & $135.5 \pm 97.9$ & 0.994 \\
\hline Leukocyte $\left(\times 10^{9}\right)$ & $8.5 \pm 3$ & $8.5 \pm 3.2$ & 0.872 \\
Platelet $\left(\times 10^{9}\right)$ & $238 \pm 53.6$ & $225 \pm 75.6$ & 0.118 \\
\hline Hemoglobin $(\mathrm{g} / \mathrm{dl})$ & $12.6 \pm 1.5$ & $12.9 \pm 1.5$ & 0.237 \\
\hline
\end{tabular}

Data are shown as mean \pm standard deviation or $\mathrm{n}(\%)$ 


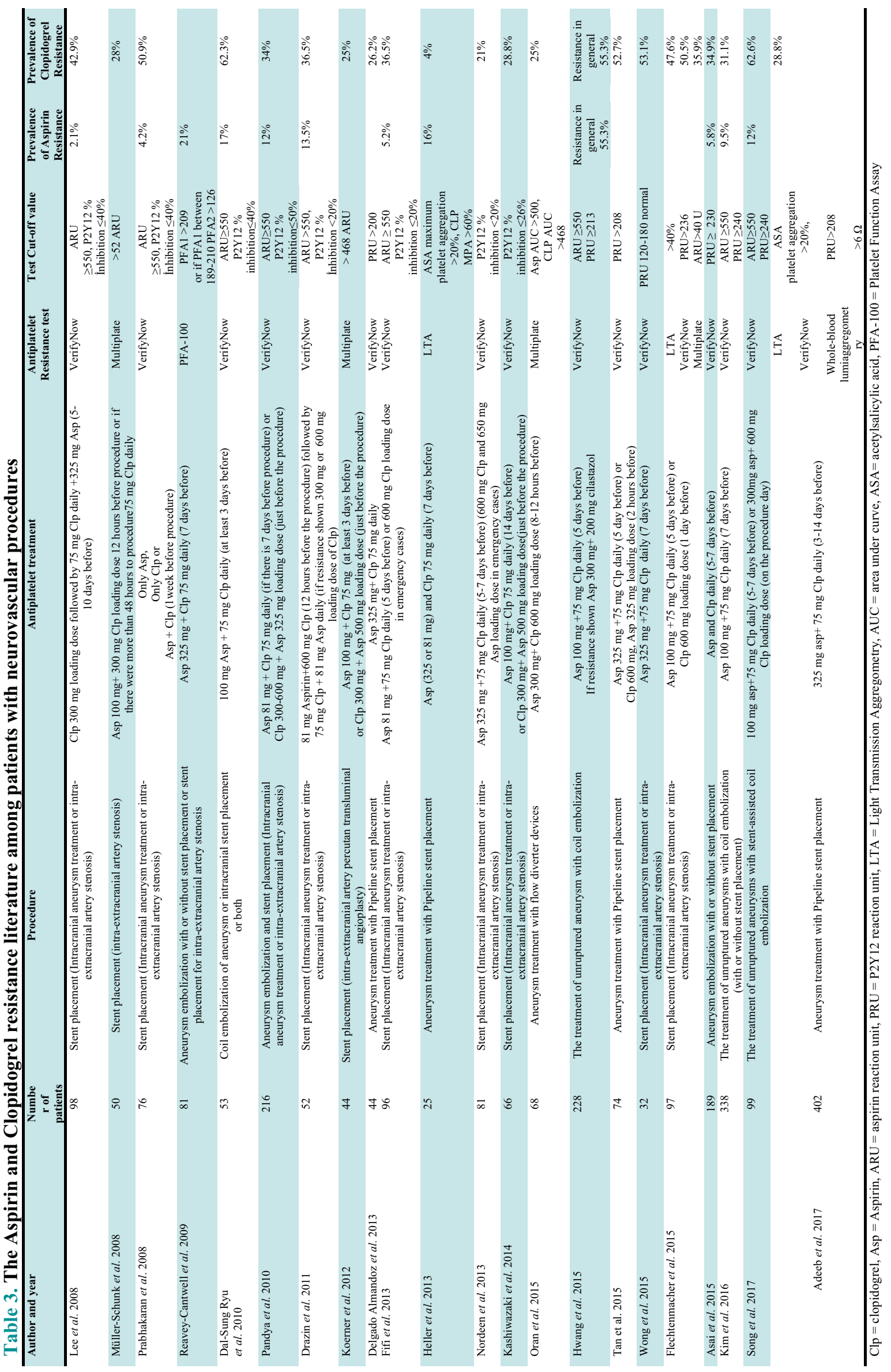


$20.7 \%$ and $25.4 \%$, respectively. Aspirin resistance was significantly higher in the latter group compared to the former $(p<0.001)$. However, there was no difference between these two groups in terms of clopidogrel resistance. The resistance frequency in the patients who had flow diverter device was $17.6 \%$ for aspirin and $25.7 \%$ for clopidogrel.

\section{DISCUSSION}

In patients undergoing cerebrovascular stenting, development of thromboembolic complications due to platelet aggregation induced by usage of endovascular devices is the main problem [2]. Dual antiplatelet therapy with asprin and clopidogrel has been accepted as premedication method and post-procedural treatment in order to prevent these complications. However, the use of platelet function tests before neurosurgical procedures remains controversial. In contrast to lack of literature in neuravascular patients, the frequency of aspirin and clopidogrel resistance has been shown in different groups of patients receiving dual antiplatelet therapy (percutaneous coronary intervention, peripheral arterial disease, ischemic stroke, diabetes mellitus, etc.) and its effect on clinical outcomes is discussed [3, 5-10].

Several studies in the cardiology literature have shown that the incidence of aspirin resistance varies according to how it is defined and the differences in dosage and population used. The prevalence of aspirin resistance in patients undergoing percutaneous coronary intervention has been in a wide range of $1-55 \%$ [5]. In addition, clopidogrel resistance has been reported up to $35 \%$ in that patient group so far [3]. However, a number of multicenter, randomized controlled trials (GRAVITAS, ARCTIC, TRIGGER-PC), which were subsequently performed in patients with percutaneous coronary interventional procedures, did not show the overall clinical benefit of antiplatelet therapy according to the results of platelet function tests [6-8].

In studies conducted into patients with peripheral arterial disease, the incidence of aspirin resistance has been reported up to $60 \%$ and clopidogrel resistance up to $65 \%$ [9]. In several studies on ischemic stroke patients, aspirin and clopidogrel resistance rate was found to be $23 \%$ and $27 \%$, respectively. Moreover, the risk of recurrent ischemic stroke or transient ischemic attack was reported higher in those patients with resistance to antiplatelets [10].

In patients undergoing neurovascular interventional procedures, platelet resistance tests, frequency of resistance and their association with clinical outcomes have been investigated in retrospective, singlecenter studies. In our study, the frequency of resistance was found to be $9.4 \%$ for aspirin and $23.8 \%$ for clopidogrel by Multiplate ${ }^{\circledR}$ test and they were similar to the frequency rates found in in the studies conducted so far. In these studies the prevelance of aspirin resistance was found to be between $2.1-17 \%$ and the frequency of clopidogrel resistance was found between 21-62.6\% (Table 3) [2, 4, 11-28].

The patients with flow diverter stents evaluated seperately given the being more excessively used in last ten years and the frequency of resistance was found to be $17.6 \%$ for aspirin and $25.7 \%$ for clopidogrel in 35 patients with flow diverter devices at our hospital. Delgado Almandoz et al. [14] and Heller et al. [23] found the low response rate of clopidogrel in patients who underwent aneurysm treatment with flow diverter devices $26.2 \%(n=44)$ and $4 \%(n=24)$, respectively. Oran et al. [4] revealed the low response rate of clopidogrel to be $25 \%(n=100)$ with Multiplate ${ }^{\circledR}$ test in a group of patients with FDD and this rate is similar to ours. Moreover, Tan et al. [24] found the frequency of low response to clopidogrel to be $52.7 \%(n=74)$ using FDD by VerifyNow test, which is the highest frequency of resistance reported to clopidogrel among patients with FDD.

The premedications with new antiplatelets, such as prasugrel and ticagrelor, are becoming increasingly used in neurovascular stenting, particularly with FDDs. In our unit, we prefer ticlopidine and prasugrel as premedication in patients who are resistant to clopidogrel. In a systematic review, dual antiplatelet regimens including ticagrelor or prasugrel are found to be safe for patients undergoing FDD procedures [29]. Besides, in another research, it was demonstrated that more than $98 \%$ of patients were within the optimal range with Multiplate ${ }^{\circledR}$ test after half-dose $(30 \mathrm{mg})$ loading of prasugrel [30].

Although there are several ways of detecting platelet aggretation inhibition, Multiplate ${ }^{\circledR}$ test is used as resistance test in our center. Flechtenmacher et al. [28] compared antiplatelet resistance with LTA, VerifyNow and Multiplate ${ }^{\circledR}$ test in 97 patients who under- 
went cerebrovascular stenting and found clopidogrel resistance to $47.6 \%, 50.5 \%$ and $35.9 \%$, respectively. Accordingly, the highest resistance frequency was determined by VerifyNow test and the lowest resistance was reported by Multiplate ${ }^{\circledR}$ test. In the same study, the correlation between resistance results reported with LTA test and the risk of thromboembolic complications was found to be better than Multiplate ${ }^{\circledR}$ and VerifyNow tests. The LTA test is the gold standard for antiplatelet resistance; however, it is a time consuming test because of necessity to be used in a laboratory environment. The tests that can be performed patientbased are Multiplate ${ }^{\circledR}$ and VerifyNow. The VerifyNow test is widely used because it has the same principle as the LTA test and is a fully automated system. The Multiplate $^{\circledR}$ test is a semi-automated system and can be performed at the bedside, such as VerifyNow, in the presence of trained stuffs [31].

As it can be understood from studies ever published, there is variability in the dose and duration of antiplatelet therapy and the cut-off values of antiplatelet resistance, as well as the patient population and stent indication in patients undergoing neurovascular procedure (Table 3). Therefore, it is inevitable that the frequency of resistance ranges in a wide variation. The general term is the presence of a group of patients in whom platelet inhibition is not sufficient despite dual antiplatelet therapy. However, there are usually single-center, retrospective studies investigating the prognosis in this patient group.

In our study, the frequency of detecting thromboembolic findings by radiological methods in patients with aspirin or clopidogrel resistance was lower in the resistant group but there was no statistically significant difference between the two groups. However, we reckon that the reason for the lower rate of thromboembolism in the resistant group is the change of medication in the patients who was with resistance to clopidogrel. Shim et al., in their meta-analysis, which reviewed the studies performed on patients undergoing neurosurgical procedures, emphasized that patients resistant to antiplatelet treatments had a higher risk of thromboembolic events than those with normal responses. They found stent placement was associated with thromboembolic risk in the resistant group in patients undergoing neurosurgical procedures. In addition, studies suggesting that re-regulated antiplatelet therapy regimens may help to reduce the risk of throm- boembolic events in patients with resistance demonstrated by antiplatelet resistance test. However, due to the variable results between single-center studies, they emphasized that cautious approach should be taken among adjusting antiplatelet therapy with the results of antiplatelet resistance tests [32].

\section{Limitations}

Our study has some limitations. The most important one is that it is a single-centered study. Hence, it reflects the frequency of drug resistance on a single region. In addition, the effect of aspirin and clopidogrel resistance on clinical outcomes could not be evaluated due to the regulation of medication after resistance was demonstrated and absence of a control group owing to retrospective design of the study.

\section{CONCLUSION}

In conclusion, in this study the incidence of aspirin resistance was $9.4 \%$ and clopidogrel resistance was $23.8 \%$ in patients who underwent neurovascular stenting. The frequency of antiplatelet resistance is very variable among these patients, mainly due to variency in the patient population, stent indication, dose-duration of antiplatelet therapy administered and the tests used to determine antiplatelet resistance as well as the cut-off values of the tests. However, as it is seen in our study, there is a group of patients who do not have sufficient platelet aggregation inhibition despite antiplatelet therapy. For this reason, the resistant patient group can be determined by performing platelet inhibitation tests before the interventional procedure. The presence of antiplatelet resistance in these patients and the effect of individual-based antiplatelet therapy on clinical outcomes should be investigated in prospective randomized controlled trials.

\section{Authors' Contribution}

Study Conception: DA, HD, ŞO, MS; Study Design: DA, HD, ŞO, MS; Supervision: DA, HD, ŞO, MS; Funding: DA; Materials: DA; Data Collection and/or Processing: DA, HD, ŞO, MS; Statistical Analysis and/or Data Interpretation: DA, HD, ŞO, MS; Literature Review: DA, HD, ŞO, MS; Manuscript Preparation: DA, HD, ŞO, MS and Critical Review: DA, HD, ŞO, MS. 


\section{Conflict of interest}

The authors disclosed no conflict of interest during the preparation or publication of this manuscript.

\section{Financing}

The authors disclosed that they did not receive any grant during conduction or writing of this study.

\section{REFERENCES}

1. Fiorella D, Thiabolt L, Albuquerque FC, Deshmukh VR, McDougall CG, Rasmussen PA. Antiplatelet therapy in neuroendovascular therapeutics. Neurosurg Clin N Am 2005;16:517-40. 2. Qureshi AI, Luft AR, Sharma M, Guterman LR, Hopkins LN. Prevention and treatment of thromboembolic and ischemic complications associated with endovascular procedures: Part II--Clinical aspects and recommendations. Neurosurgery 2000;46:1360-75; discussion 1375-6.

3. Bonello L, Tantry US, Marcucci R, Blindt R, Angiolillo DJ, Becker R, et al. Consensus and future directions on the definition of high on-treatment platelet reactivity to adenosine diphosphate. J Am Coll Cardiol 2010;56:919-33.

4. Oran I, Cinar C, Bozkaya H, Korkmaz M. Tailoring platelet inhibition according to multiple electrode aggregometry decreases the rate of thrombotic complications after intracranial flow-diverting stent implantation. J Neurointerv Surg 2015;7:357-62.

5. Tantry US, Mahla E, Gurbel PA. Aspirin resistance. Prog Cardiovasc Dis 2009;52:141-52.

6. Price MJ. Standard- vs high-dose clopidogrel based on platelet function testing after percutaneous coronary intervention. JAMA 2011;305:1097.

7. Collet J-P, Cuisset T, Rangé G, Cayla G, Elhadad S, Pouillot $\mathrm{C}$, et al. Bedside monitoring to adjust antiplatelet therapy for coronary stenting. N Engl J Med 2012;367:2100-9.

8. Trenk D, Stone GW, Gawaz M, Kastrati A, Angiolillo DJ, Müller U, et al. A randomized trial of prasugrel versus clopidogrel in patients with high platelet reactivity on clopidogrel after elective percutaneous coronary intervention with implantation of drug-eluting stents. J Am Coll Cardiol 2012;59:2159-64.

9. Guirgis M, Thompson P, Jansen S. Review of aspirin and clopidogrel resistance in peripheral arterial disease. J Vasc Surg 2017;66:1576-86.

10. Fiolaki A, Katsanos AH, Kyritsis AP, Papadaki S, Kosmidou M, Moschonas IC, et al. High on treatment platelet reactivity to aspirin and clopidogrel in ischemic stroke: a systematic review and meta-analysis. J Neurol Sci 2017;376:112-6.

11. Asai T, Miyachi S, Izumi T, Matsubara N, Haraguchi K, Yamanouchi T, et al. Relationship between low response to clopidogrel and periprocedural ischemic events with coil embolization for intracranial aneurysms. J Neurointerv Surg 2016;8:752-5.

12. Drazin D, Choulakian A, Nuno M, Kornbluth P, Alexander MJ. Body weight: a risk factor for subtherapeutic antithrombotic therapy in neurovascular stenting. J Neurointerv Surg
2011;3:177-81.

13. Lee DH, Arat A, Morsi H, Shaltoni H, Harris JR, Mawad ME. Dual antiplatelet therapy monitoring for neurointerventional procedures using a Point-of-Care platelet function test: a single-center experience. Am J Neuroradiol 2008;29:1389-94.

14. Delgado Almandoz JE, Crandall BM, Scholz JM, Fease JL, Anderson RE, Kadkhodayan Y, et al. Pre-procedure P2Y12 reaction units value predicts perioperative thromboembolic and hemorrhagic complications in patients with cerebral aneurysms treated with the Pipeline Embolization Device. J Neurointerv Surg 2013;5 Suppl 3:iii3-10.

15. Fifi JT, Brockington C, Narang J, Leesch W, Ewing SL, Bennet $\mathrm{H}$, et al. Clopidogrel resistance is associated with thromboembolic complications in patients undergoing neurovascular stenting. AJNR Am J Neuroradiol 2013;34:716-20.

16. Kashiwazaki D, Kuwayama N, Akioka N, Hayakawa Y, Kuroda S. The roles and issues of P2Y12 percent inhibition assessed by VerifyNow assay for patients undergoing neurointervention: a prospective study. J Stroke Cerebrovasc Dis 2014;23:1830-6.

17. Koerner H, Derveaux C, Alexandrou M, Graeber S, Roth C, Papanagiotou $\mathrm{P}$, et al. Do clopidogrel nonresponders have an increased risk of adverse events during supra-aortal angioplasty and stenting? Stroke Res Treat 2012;2012:904534.

18. Müller-Schunk S, Linn J, Peters N, Spannagl M, Deisenberg M, Brückmann H, et al. Monitoring of clopidogrel-related platelet inhibition: correlation of nonresponse with clinical outcome in supra-aortic stenting. Am J Neuroradiol 2008;29:786-91.

19. Pandya D, Fitzsimmons B, Wolfe T, Hussain S, Lynch J, Ortega-Gutierrez S, et al. Measurement of antiplatelet inhibition during neurointerventional procedures: the effect of antithrombotic duration and loading dose. J Neuroimaging 2010;20:64-9. 20. Wong P, Tesoro E, Aletich V, Alaraj A. Accumetrics-based clopidogrel dosing in endovascular neurosurgery. Neurol Res 2015;37:998-1005.

21. Song J, Shin YS. Antiplatelet drug resistance did not increase the thromboembolic events after stent-assisted coiling of unruptured intracranial aneurysm: a single center experience of 99 cases. Neurol Sci 2017;38:879-85.

22. Nordeen JD, Patel A V, Darracott RM, Johns GS, Taussky P, Tawk RG, et al. Clopidogrel resistance by P2Y12 platelet function testing in patients undergoing neuroendovascular procedures: incidence of ischemic and hemorrhagic complications. J Vasc Interv Neurol 2013;6:26-34.

23. Heller RS, Dandamudi V, Lanfranchi M, Malek AM. Effect of antiplatelet therapy on thromboembolism after flow diversion with the Pipeline Embolization Device. J Neurosurg 2013;119:1603-10.

24. Tan LA, Keigher KM, Munich SA, Moftakhar R, Lopes DK. Thromboembolic complications with Pipeline Embolization Device placement: impact of procedure time, number of stents and pre-procedure P2Y12 reaction unit (PRU) value. J Neurointerv Surg 2015;7:217-21.

25. Nishi H, Nakahara I, Matsumoto S, Hashimoto T, Ohta T, Sadamasa N, et al. Platelet reactivity and hemorrhage risk in neurointerventional procedures under dual antiplatelet therapy. J Neurointerv Surg 2016;8:949-53. 
26. Reavey-Cantwell JF, Fox WC, Reichwage BD, Fautheree GL, Velat GJ, Whiting JH, et al. Factors associated with aspirin resistance in patients premedicated with aspirin and clopidogrel for endovascular neurosurgery. Neurosurgery 2009;64:890-6.

27. Ryu D-S, Hong C-K, Sim Y-S, Kim C-H, Jung J-Y, Joo J-Y. Anti-platelet drug resistance in the prediction of thromboembolic complications after neurointervention. J Korean Neurosurg Soc 2010;48:319.

28. Flechtenmacher N, Kämmerer F, Dittmer R, Budde U, Michels $\mathrm{P}$, Röther J, et al. Clopidogrel resistance in neurovascular stenting: correlations between light transmission aggregometry, VerifyNow, and the Multiplate. Am J Neuroradiol 2015;36:19538.

29. Podlasek A, Al Sultan AA, Assis Z, Kashani N, Goyal M,
Almekhlafi MA. Outcome of intracranial flow diversion according to the antiplatelet regimen used: a systematic review and meta-analysis. J Neurointerv Surg 2020;12:148-55.

30. Oran I, Cinar C, Gok M, Duzgun F. Aggregometry response to half-dose prasugrel in flow-diverting stent implantation. Clin Neuroradiol 2020;30:463-9.

31. Oran I, Cinar C. Nöroendovasküler Girişimsel Tedavilerde Anti-trombotik İlaç Kullanımı. Türk Radyoloji Semin 2018;6:1126.

32. Shim EJ, Ryu C-W, Park S, Lee HN, Shin HS, Kim S-B. Relationship between adverse events and antiplatelet drug resistance in neurovascular intervention: a meta-analysis. J Neurointerv Surg 2018;10:942-8. 